\title{
Seasonal variation in proline contents in several halophytes from a littoral salt marsh in Alicante (SE Spain)
}

\author{
*Grigore Marius-Nicusor, **Monica Boscaiu, *Oscar Vicente \\ *Faculty of Biology, Alexandru Ioan Cuza University, Carol I, 20 A, 700505 Iasi, Romania \\ e-mail: mariusgrigorepsyche@yahoo.com \\ **Instituto de Biología Molecular y Celular de Plantas, Instituto Agroforestal Mediterráneo, \\ Universitat Politècnica de València, Camino de Vera s/n, 46022 Valencia, Spain
}

\begin{abstract}
Summary. In the present study, we have investigated spatial and temporal changes in Pro levels in several monocotyledonous and dicotyledonous halophytes growing in a littoral salt marsh located near the city of Alicante (SE Spain).
\end{abstract}

Key words: halophytes, salt stress, proline, natural conditions.

\section{Introduction}

Proline (Pro), probably the most common osmolyte used by plants, accumulates in many species in parallel with an increase in external salinity, and is considered as a reliable biochemical marker of salt stress.

\section{Material and methods}

The material subjected to analysis in the present study was divided in two groups. From the first group, two species of the genus Juncus were selected, J. maritimus and J. acutus; they are closely related taxonomically but, according to their ecology and distribution in nature, J. maritimus appears to be more salt tolerant than J. acutus, which is rather subhalophilic. The study also included three succulent dicotyledonous species: Sarcocornia fruticosa and Arthrocnemum macrostachyum (Amaranthaceae) - two taxa very similar morphologically, even though they are classified in different genera - as well as Inula crithmoides (Asteraceae). Within the salt marsh under study, four ex- perimental plots $(6 \times 5 \mathrm{~m})$ were defined in a salinity gradient, with two of them located in the central, lower area of the marsh and considerably more saline than the other two at the edge. Culms or young shoots were sampled from all selected species, in summer and autumn 2010 - on July $15^{\text {th }}$ and November $28^{\text {th }}$, respectively. Plant material was cooled on ice, transported to the laboratory and stored frozen at $-75^{\circ} \mathrm{C}$, until used for the spectrophotometric determination of Pro (according to the modified Bates' method (Bates et al. 1972).

\section{Results and discussions}

We could not detect statistically significant correlations between Pro levels and soil salinity, for any of the studied species growing in the different plots, neither in the summer nor in the autumn sampling; however, should it be mentioned that in the statistical analysis small differences would be masked by the relatively high variability of the Pro contents of individual plants. When comparing the two Juncus species, under all tested environmental conditions 
Pro levels were higher in J. maritimus - as we had also determined in previous analyses performed with plants from other salt marshes - in agreement with the differences in salt tolerance of the two taxa. These data suggest that Pro accumulation is an important contributing factor to the salt tolerance mechanisms of Juncus in their natural habitats.

Regarding seasonal differences, Pro levels did not vary significantly in I. crithmoides or S. fruticosa - species which accumulate glycine betaine and probably do not use Pro as the major osmolyte - but were clearly higher in the samples collected in autumn, for the other three taxa: A. macrostachyum (about 2.7-fold), J. acutus (2.5-fold) and J. maritimus (3.3-fold). In 2010, in the zone under study whether conditions were much drier during the four months previous to the summer sampling - with $113 \mathrm{~mm}$ precipitation $(\mathrm{P})$ and $440 \mathrm{~mm}$ evapotranspiration $(\mathrm{ET})-$ than from the first to the second sampling $(\mathrm{P}=58 \mathrm{~mm}$, ET $=548 \mathrm{~mm}$ ). It appears, therefore, that Pro contents correlate best with the accumulated hydric deficit to which the plants are subjected.

\section{Aknowledgements}

Supported by grants from the Spanish Ministry of Science and Innovation, with contribution from the European Regional Development Fund (project CGL2008-00438/BOS) to O.V., and from Polytechnic University of Valencia (programme 'PAID-06-09') to M.B. M.-N.G. acknowledges the support provided by COST Action FA0901 for his stay in Valencia in the frame of a Short Term Scientific Mission, and by the Romanian POSDRU/89/1.5/S/49944 project "Developing the innovation capacity and improving the impact of research through post-doctoral programmes”.

\section{References}

Bates L. S., Waldren R. P. \& Teare I. D., 1972, Rapid determination of free proline for water stress studies, Plant and Soil 39: 205-207. 